\title{
COSINE OF ANGLE BETWEEN TWO VECTORS
}

\author{
S. R. Searle
}

Biometrics Unit, Cornell University, Ithaca, N. Y. 14853

BU-1343-M

June 1996

$\underline{\text { Abstract }}$

This is an invited 500-word article for an upcoming Encyclopedia of Biostatistics. It derives the result for 2-space, refers to a detailed triangle-based derivation for 3-space, and quotes the result for $\mathrm{n}$-space. An invariance property and a connection to correlation are noted.

Key words

2-space, 3-space, n-space, right-angled triangles, invariance, correlation. 


\title{
COSINE OF ANGLE BETWEEN TWO VECTORS
}

\author{
S. R. Searle \\ Biometrics Unit, Cornell University, Ithaca, N. Y. 14853
}

\section{TWO-SPACE}

Two vectors in 2-space are shown in Figure 1 with $\left(\mathrm{x}_{1}, \mathrm{x}_{2}\right)$ being a point on one vector and $\left(\mathrm{y}_{1}\right.$, $y_{2}$ ) on the other.

\section{[Show Figure 1]}

Let $A_{x}$ and $A_{y}$ be the angles the vectors make with the horizontal axis, and define $B$ as the angle between the vectors. Thus

$$
\begin{aligned}
\mathrm{B} & =\mathrm{A}_{x}-\mathrm{A}_{y} \\
\cos \mathrm{B} & =\cos \left(\mathrm{A}_{x}-\mathrm{A}_{y}\right) \\
& =\cos \mathrm{A}_{x} \cos \mathrm{A}_{y}+\sin \mathrm{A}_{x} \sin \mathrm{A}_{y} .
\end{aligned}
$$

On dropping perpendiculars from the points to the horizontal axis, it is then easily seen from rightangle triangle geometry that

$$
\begin{aligned}
\cos \mathrm{B} & =\frac{\mathrm{x}_{1}}{\left(\mathrm{x}_{1}^{2}+\mathrm{x}_{2}^{2}\right)^{\frac{1}{2}}} \frac{\mathrm{y}_{1}}{\left(\mathrm{y}_{1}^{2}+\mathrm{y}_{2}^{2}\right)^{\frac{1}{2}}}+\frac{\mathrm{x}_{2}}{\left(\mathrm{x}_{1}^{2}+\mathrm{x}_{2}^{2}\right)^{\frac{1}{2}}} \frac{\mathrm{y}_{2}}{\left(\mathrm{y}_{1}^{2}+\mathrm{y}_{2}^{2}\right)^{\frac{1}{2}}} \\
& =\frac{\mathrm{x}_{1} \mathrm{y}_{1}+\mathrm{x}_{2} \mathrm{y}_{2}}{\mathrm{~d}_{x} \mathrm{~d}_{y}}
\end{aligned}
$$

for

$$
\mathrm{d}_{x}^{2}=\mathrm{x}_{1}^{2}+\mathrm{x}_{2}^{2} \quad \text { and } \quad \mathrm{d}_{y}^{2}=\mathrm{y}_{1}^{2}+\mathrm{y}_{2}^{2} .
$$

Thus (2) is the formula for the cosine of the angle between two vectors in 2-space.

\section{THREE-SPACE}

For two vectors in 3-space a diagram analogous to Figure 1 can be drawn. Applying to that some triangle geometry more complicated than that used for deriving (1) yields the result

$$
\cos \mathrm{B}=\frac{\mathrm{x}_{1} \mathrm{y}_{1}+\mathrm{x}_{2} \mathrm{y}_{2}+\mathrm{x}_{3} \mathrm{y}_{3}}{\mathrm{~d}_{x} \mathrm{~d}_{y}}
$$

with

$$
\mathrm{d}_{x}^{2}=\mathrm{x}_{1}^{2}+\mathrm{x}_{2}^{2}+\mathrm{x}_{3}^{2} \quad \text { and } \quad \mathrm{d}_{y}^{2}=\mathrm{y}_{1}^{2}+\mathrm{y}_{2}^{2}+\mathrm{y}_{3}^{2}
$$


where $\left(\mathrm{x}_{1}, \mathrm{x}_{2}, \mathrm{x}_{3}\right)$ is a point on one vector and $\left(\mathrm{y}_{1}, \mathrm{y}_{2}, \mathrm{y}_{3}\right)$ is on the other. Details are shown in Searle (1996).

\section{N-SPACE}

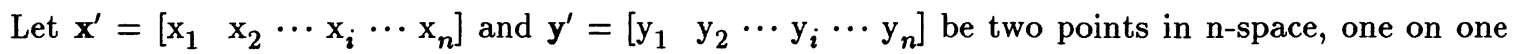
vector and one on another. Then results (2), (3) and (4), (5) extend very directly for n-space to

$$
\cos \mathrm{B}=\sum_{i=1}^{n} \mathrm{x}_{i} \mathrm{y}_{i} / \mathrm{d}_{x} \mathrm{~d}_{y}
$$

for

$$
\mathrm{d}_{x}^{2}=\sum_{i=1}^{n} \mathrm{x}_{i}^{2} \quad \text { and } \quad \mathrm{d}_{y}^{2}=\sum_{i=1}^{n} \mathrm{y}_{i}^{2}
$$

so that, in terms of the vectors $\mathbf{x}^{\prime}$ and $\mathbf{y}^{\prime}$

$$
\cos B=x^{\prime} \mathbf{y} / \sqrt{x^{\prime} \mathbf{x}} \sqrt{\mathbf{y}^{\prime} \mathbf{y}} .
$$

Viewed from the geometry of two and three dimensions, (6) may not seem very satisfying. Moreover, its derivation demands arguments in the geometry of n-space. These arguments are more theoretical than those for deriving (2) and (4) of 2-space and 3-space, respectively. Thus it is easier to simply take (6) as an algebraic definition of $\mathrm{B}$ as the angle between two vectors in $\mathrm{n}$-space. Indeed, some books on multivariate statistical analysis do just that, e.g., Mardia et al. (1979, p. 16) and Johnson and Wichern (1988, p. 99).

\section{INVARIANCE}

The prime property of a vector is its direction, not its length. Yet each of (2), (4) and (6) seem to depend upon the actual values of the xs and the ys, i.e., their lengths. Fortunately this is not so. For example, with (2), if on the vector through $\left(\mathrm{x}_{1}, \mathrm{x}_{2}\right)$ some other point $\left(\mathrm{x}_{1}^{*}, \mathrm{x}_{2}^{*}\right)$ is taken, it will be found from the geometry of congruent triangles that if $x_{1}^{*}=\lambda_{x} x_{1}$ then $x_{2}^{*}=\lambda_{x} x$. Therefore $\cos \theta$ of (2) with $\mathrm{x}^{*}$ s and $\mathrm{y}^{*} \mathrm{~s}$ replacing $\mathrm{xs}$ and ys becomes

$$
\begin{aligned}
\cos \mathrm{B} & =\frac{\mathrm{x}_{1}^{*} \mathrm{y}_{1}^{*}+\mathrm{x}_{2}^{*} \mathrm{y}_{2}^{*}}{\left(\mathrm{x}_{1}^{*^{2}}+\mathrm{x}_{2}^{*^{2}}\right)^{\frac{1}{2}}\left(\mathrm{y}_{1}^{*^{2}}+\mathrm{y}_{2}^{*^{2}}\right)^{\frac{1}{2}}}=\frac{\lambda_{x} \lambda_{y}\left(\mathrm{x}_{1} \mathrm{y}_{1}+\mathrm{x}_{2} \mathrm{y}_{2}\right)}{\lambda_{x}\left(\mathrm{x}_{1}^{2}+\mathrm{y}_{1}^{2}\right)^{\frac{1}{2}} \lambda_{y}\left(\mathrm{y}_{1}^{2}+\mathrm{y}_{2}^{2}\right)^{\frac{1}{2}}} \\
& =\left(\mathrm{x}_{1} \mathrm{y}_{1}+\mathrm{x}_{2} \mathrm{y}_{2}\right) / \mathrm{d}_{1} \mathrm{~d}_{2}
\end{aligned}
$$


as before; i.e., cos B of (2) is unchanged. Similar geometry also leaves (4) unchanged. And arguing in n-space that. changing $x_{1}$ to $x_{1}^{*}=\lambda_{x} x_{1}$ leads to $x_{i}^{*}=\lambda_{x} x_{i} \forall i$, then (6) will be unchanged also.

\section{CORRELATION}

When the entries in $\mathbf{x}$ and $\mathbf{y}$ are data (e.g., height and weight of each member of a rowing club),

define $\bar{x}$ and $\bar{y}$ as the observed averages: $\bar{x}=\sum_{i=1}^{n} x_{i} / n$ and $\bar{y}=\sum_{i=1}^{n} y_{i} / n$. In $x$ and $y$ replace each element $\mathrm{x}_{i}$ by $\mathrm{x}_{i 0}=\mathrm{x}_{i}-\overline{\mathrm{x}}$ and $\mathrm{y}_{i}$ by $\mathrm{y}_{i 0}=\mathrm{y}_{i}-\overline{\mathrm{y}}$. Define $\mathrm{x}_{0}$ and $\mathrm{y}_{0}$ as the vectors of elements $\mathrm{x}_{i 0}$ and $\mathrm{y}_{i 0}$. Then $\cos \mathrm{B}$ for $\mathrm{x}_{0}$ and $\mathrm{y}_{0}$ is

$$
\cos \mathrm{B}=\frac{\mathrm{x}_{0}^{\prime} \mathrm{y}_{0}}{\left(\mathrm{x}_{0}^{\prime} \mathrm{x}_{0}\right)^{\frac{1}{2}}\left(\mathrm{y}_{0}^{\prime} \mathrm{y}_{0}\right)^{\frac{1}{2}}}=\frac{\sum_{i=1}^{n}\left(\mathrm{x}_{i}-\overline{\mathrm{x}}\right)\left(\mathrm{y}_{i}-\overline{\mathrm{y}}\right)}{\left[\sum_{i=1}^{n}\left(\mathrm{x}_{i}-\overline{\mathrm{x}}\right)^{2}{ }_{i=1}^{n}\left(\mathrm{y}_{i}-\overline{\mathrm{y}}\right)^{2}\right]^{\frac{1}{2}}}
$$

is the product-moment correlation between the two variables.

\section{References}

Johnson, R.A. and Wichern, D.W. (1988) Applied Multivariate Statistical Analysis, 3rd Ed., Prentice Hall.

Mardia, K.V., Kent, J.T., and Bibby, J.M. (1979) Multivariate Analysis, Academic Press.

Searle, S.R. (1996) Technical Report BU-1342-M, Biometrics Unit, Cornell University. 


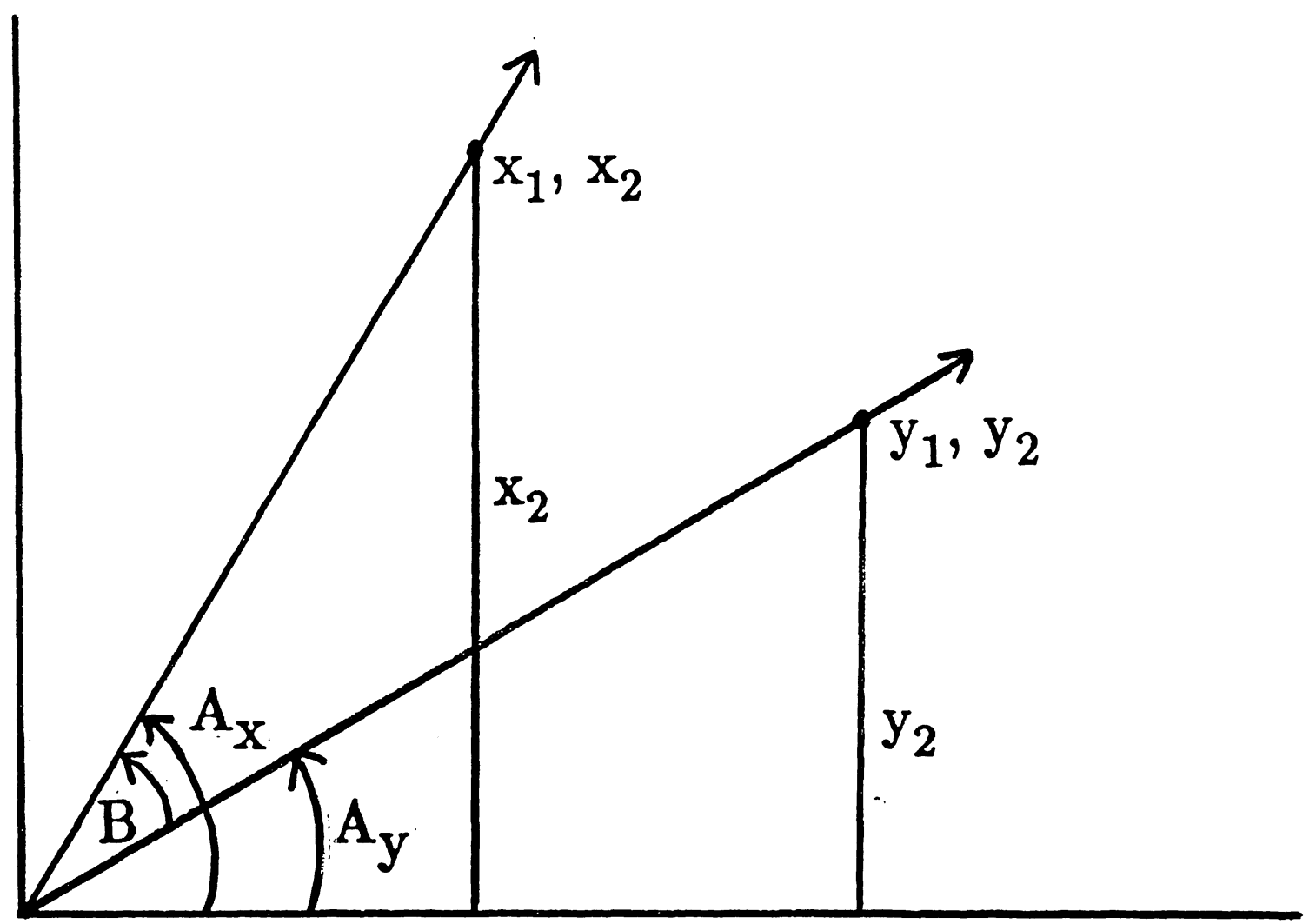

Figure 1: Two vectors in 2-space. 